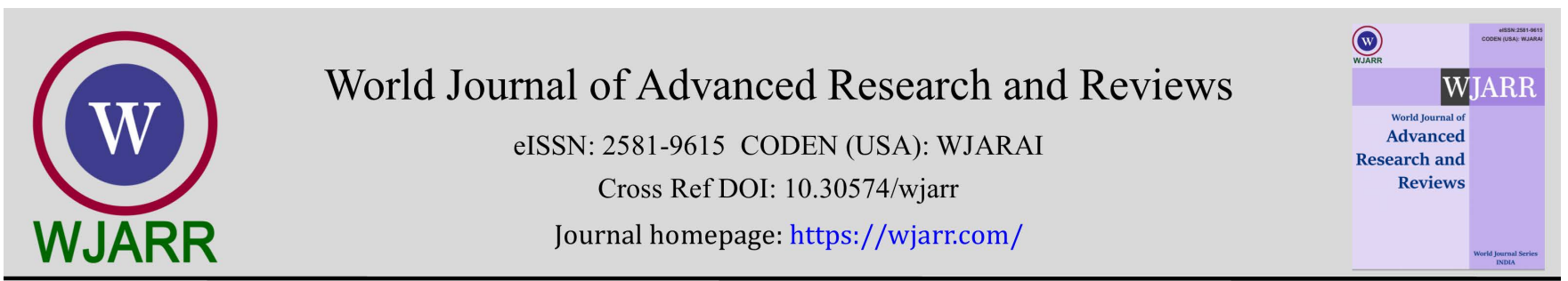

(REview ARTICLE)

Check for updates

\title{
Adequacy of sample size in a qualitative case study and the dilemma of data saturation: A narrative review
}

\author{
Felix Chukwuma Aguboshim * \\ Department of Computer Science, Federal Polytechnic, Oko, Anambra State. Nigeria.
}

World Journal of Advanced Research and Reviews, 2021, 10(03), 180-187

Publication history: Received on 07 May 2021; revised on 10 June 2021; accepted on 12 June 2021

Article DOI: https://doi.org/10.30574/wjarr.2021.10.3.0277

\begin{abstract}
The consensus of many researchers on data saturation is that data saturation is a key driver for determining the adequacy of sample size in a qualitative case study. Despite these global consensuses, some researchers described data saturation as complex because the decision to stop data collection is solely dictated by the judgment and experience of researchers. Other researchers claimed that guidelines for determining non-probability sample sizes, used as an indication of data saturation are virtually non-existent, problematic, or controversial. Others claimed that data saturation hitched to sample size is practically weak, because data are never truly saturated, as there are always new data to be discovered. This narrative study highlights the dilemma of data saturation and strategies to adequately determine sample size in a qualitative case study. A narrative review of prior research that focused on the vast works of literature that revealed significant information on data saturation and strategies to adequately determine sample size was adopted. Peer-reviewed articles within the last five years from electronic databases, using some keywords such as "qualitative case study", "sample size in a qualitative case study", "data saturation", etc., were also extracted. Results show that data saturation is very helpful especially at the conceptual stage, but its concept and standard is elusive, because it lacks practical guidance for estimating sample size for a robust research prior to data collection. Findings from this study may encourage researcher on better guidelines for determining non-probability sample sizes.
\end{abstract}

Keywords: Data saturation; Qualitative case study; Non-probability sample size; Qualitative data collection; New data

\section{Introduction}

The adequacy of the sample size determined by the concept of data saturation that brings in new participants continually into the study until there are no new information in the data set, as indicated by data redundancy or data replication is the view of many qualitative case study researchers [9], [26], [36], [39], [49] and [60]. Data saturation is reached when the gathering of data by the researcher tends to a point of diminishing returns, when no new data are being added; implying that estimation of sample size in a qualitative case study is a direct function of data saturation concept [39]. Data saturation is reached when additional input from new participants do not continue to generate new information, or generate new themes, or continue to impact new understanding of the study topic, as revealed by the themes and sub-themes [34]. The idea of data saturation is very helpful especially at the conceptual stage, but its concept and standard are elusive because it does not provide enough practical guidance for estimating sample size for a robust research prior to data collection [39]. Some qualitative case study researchers have openly recognized the lack of standards for sample size estimation for data saturation [9], [17], and [39]. There are no published standard guidelines for estimating sample size that will reach saturation in a qualitative case study [23].

\footnotetext{
* Corresponding author: Felix C Aguboshim

Department of Computer Science, Federal Polytechnic, Oko , Anambra State. Nigeria.
} 
The concept of assuming data saturation just because one has exhausted the resources is not universally adopted or acceptable by qualitative case study researchers. Some researchers claimed that data saturation is not all about the sample size alone, but about how rich (high quality) and thick (enough quantity) the data [24] and [56]. What is important to most qualitative case study researchers are the choice of sample size that has the best opportunity for the researcher to reach data saturation whether large samples or not. Some other qualitative case study researchers claimed that the concept of data saturation is inconsistent, unrealistic, and practically untenable [23], [28] and [45]. The purpose of this narrative study is to identify some views of qualitative case study researchers on data saturation in relation to reliability and validity of findings, with the aim of recommending strategies for adequacy of sample size in a qualitative case study in the face of the dilemma of data saturation. The findings from this study may encourage social change as more qualitative case study researchers learn to adopt, without bias, the various strategies employed to ensure the rigor of the work and data saturation. This may also create new innovations and influences globally that could advance the better use of data saturation concepts especially among qualitative case study researchers.

\section{Literature Review}

Qualitative case study researchers are unlikely to agree on exact sample size required to reach saturation [39]. This is because there are no universal study designs [22], and the focus of qualitative research is generally not on sample size or generalization but on sample adequacy that can justify saturation [12]. The question is how is sampling adequacy measured or achieved? Guidelines for determining nonprobability sample sizes, used as an indication of quality, are virtually nonexistent [28], problematic [45], or controversial [23]. O'Reilly and Kiyimba challenged the concept of saturation and considered its adoption across all qualitative approaches as inappropriate, and its name as a quality marker for sampling adequacy as generic [45]. According to O'Reilly and Kiyimba, the increasingly ubiquitous discourse of data saturation has created one important and somewhat neglected argument within this field of data saturation [45]. This is because data saturation is being treated as unproblematic and increasingly accepted and expected as a marker for sampling adequacy. This idea was supported by Bowen who argues that researchers are not being frank concerning how exactly data saturation is reached in the face of its practicality in terms of time and resources, and number of participants that can be interviewed [12].

Sometimes data saturation cannot be reached [12]. Another question to be answered is, if saturation is not reached, does it invalidate the findings? The answer surely is NO. O'Reilly \& Kiyimba, and Crouch \& McKenzie explain that whether or not saturation is reached, it does not invalidate the findings; rather the findings should include the note that the phenomenon has not yet been fully explored [45] and [17]. Crouch and McKenzie opined that since qualitative research is intended for an in-depth exploration study rather than inferential or relational, the issue of sample size has little bearing on the project's validity [17]. Therefore, portraying data saturation as a quality indicator is not always relevant.

The definition of data saturation, in itself, appears to be vague. If the definition of a phenomenon is proven to be vague, so is the concept itself. For instance, if a qualitative researcher has sampled " $n$ " samples and suspected data saturation, how many additional samples should be taken to determine data saturation? It is possible to take next $(n+1)$ with no new findings while further $n+2, n+3, n+4$ samples may show new findings, and possibly $n+5, n+6$, may depict no new findings and so on. The question is how many samples the researcher will take before concluding that there is no more new information. Definitely, it is against all statistical logic to stop just because the immediate next sample showed no new information which may be a chance effect. According to Wray, et al, data saturation is practically weak, because data are never truly saturated [61]. There are always new data to be discovered [61].

\subsection{The Dilemma of data saturation}

Two researchers, Baker and Edwards, decided to interview experts on their views on the number of interviews needed for a qualitative study to reach data saturation [6]. Their first interviewee, Harry Wolcott's short answer was simply "it depends". It depends on the researcher's resources, time, cost and even how many respondents are enough to satisfy committee members for a dissertation. However, Harry Wolcott added that the usual answer is to keep asking as long as you are getting different answers [6].

Shortly Harry Wolcott put the question back to them, asking the researchers if the number of experts they decided were enough for their study. The interviewers of experts replied Harry Wolcott that they were working with an estimate of reaching data saturation, with respect to the discipline, expertise, locality, and practicability. Then Harry Wolcott insisted the researchers must supply the answer to his question. They finally replied Harry Wolcott with the answer 15 [6]. One can observe the irony here. Baker and Edwards set to find out from experts, the number of samples to reach 
saturation, yet they had a working sample size in mind before data collection [6]. Baker and Edwards interview with the quota of expert voices ended up at 14, though they planned to interview 15 [6].

Using past researches to draw conclusions is wisdom and using past assessment facilitated by the use of examples from past qualitative case study sample size that can lead to saturation can be assumed as a working guide [33]. The dilemma with a researcher suggesting that he will continue adding participants until saturation is reached is that you cannot determine that you have reached saturation until you perform analysis, but you do not perform the analysis until after you complete the interviews. It is therefore expedient for a researcher to have a working sample size in mind prior to data collection. When one does not know where one is going, everywhere will look like the place. Assuming a working sample size before data collection is necessary based on past related researches. Realizable assumptions are not out of place.

Assumptions are the basis for most statistical and scientific innovations, as real situations are never exactly realized in practice. All researchers agree that there are no correct absolute measurements to form a construct [41]. According to mood, et al., when a coin is tossed, the probability of obtaining a head is 0.5 , under the assumption that there are only two possible outcomes: head or tail [41]. Under this assumption, mathematical systems have assumed a fair, true or unbiased coin, or a coin that will never stand on its own when tossed, thereby removing completely the third possibility aside head or tail, in the outcome space. But tossing a coin and having the coin standing on itself is a possibility [41]. Geometry for example, deals with conceptual perfect circles, and lines with zero width [41]. But all of us also agree that no one has ever drawn a line with zero width. Ideal situations are never exactly realized in practice, but these are common requirements in statistical, mathematical, and other systems [32]. Researchers have recommended the adoption of sample sizes that yielded saturation for expert researchers in literature who have done similar works in the past [29].

Natoli, et al. acquired qualitative data that saturated with a sample size of thirty-five [43]. Afsharkazemi, et al., Wong et al., Schäfer et al., Atif, et al., Gonzalo et al., and Thomsen et al. got data saturation with a sample size of 9, 10, 14, 16, 34, and 15 respectively [1], [60], [49], [3], [26] and [55]. Hagaman and Wutich found that 16 or fewer interviews were enough to identify common themes with relatively homogeneous groups, but their research revealed that larger sample sizes ranging from 20 to 40 participants may reach data saturation [29]. Dare, et al conducted three qualitative case studies in different locations: PNG, Uganda, and Sierra Leone, but got data saturations with a sample size of 29, 32 and 12 in PNG, Uganda, and Sierra Leone respectively [18]. Marshall, et al, and Latham conclusively recommended that grounded theory qualitative studies should include 20 to 30 interviews, while single case study should generally contain a minimum of 15 that may saturate between 20 to 30 interviews [39, 37]. Researchers may adopt sample sizes that yielded saturation for expert researchers in literature who have done similar works in the past.

\subsection{Strategies employed to ensure the rigor of the work and data saturation}

Various strategies employed to ensure the rigor of the work and data saturation may include triangulation, member checking, audit trials, reflexivity, peer debriefing and reaching data saturation [44]. Qualitative case study approach generally calls for the use of multiple sources of data [15]. Triangulation is a process of using two or more methods to study the same phenomenon [47]. Member checking is a data collection method that establishes a back and forth conversation between the researcher and her participants around every stage of the process of data collection as a means of achieving data saturation, by giving participants the ability to read the researcher's interpretations and provide any corrections or additional information [13] and [51]. Member checking enhances data saturation by checking to examine and confirm interview data for corrections, additions or complete deletion if participant decides to back out completely. Member checking is also used to establish a back and forth conversation between the researcher and her participants throughout the processes of data collection [13], framing of the research question and vetting of semi-structured interview guide [7], data analysis and interpretation [40], individual themes and participant themes [51], presentation of findings to check if their interviews matched what they actually meant [25] and [53], and ensuring that accurate findings had been extracted from the interviews [2] and [11]. Researchers also recommended member checking as the most crucial technique for establishing validity and credibility of instruments used in a qualitative case study in other to enhance data saturation [14], [27], [30], [44], and [54].

Confirmability in a qualitative case study may be actualized through audit trails and reflexivity [59]. Triangulation in addition to audit trails and reflexivity are included in the plans to ensure confirmability [21], which in turn encourages data saturation. According to Auger, audit trails strategies aid confirmability because they serve as research study blueprint that outlines detailed procedural records usually maintained by the researcher [4]. Therefore, confirmability can be achieved when researcher's study blueprint is made accessible to an external researcher in a view to secure replication of study. On the other hand, confirmability is strengthened if a study can be replicated with similar results 
[10]. Reflexivity is a strategy employed to ensure the rigor of the study and data saturation by the researcher continuously keeping records of what s/he knows about herself and the participants in relation to the study, in a way to offset the researcher's preconceived notions about the research which might interfere with data analysis and interpretation, thereby implementing confirmability or neutrality.

\section{Methodology}

The researcher adopted a narrative review approach. Prior researches on the adequacy of sample size in a qualitative case study and the dilemma of data saturation were reviewed. A narrative study approach is best suited to a study that can be described as descriptive or explanatory [8] and [46], and where summaries of different primary studies from which conclusions may be drawn into a holistic interpretation contributed by the reviewers' own experience, existing theories and models are needed [48]. Narrative studies have great abilities and capabilities to capture and comprehend the diverse and numerous insights around scholarly research topics and the opportunity to extract from vast literature, reflective practices, shared views and knowledge [38]. In this paper, and within narrative inquiry, the author reviewed a vast of peer-reviewed articles in line with the specified key words and term identification, article identification, quality assessment, data extraction, and data synthesis.

\subsection{Data Collection}

Literature search of online information obtained from the following international library databases: the ProQuest databases, Science Direct, Walden University collection of scholarly and peer-reviewed journals, and other related texts, were reviewed using the key search words in the databases for related literature on adequacy of sample size in a qualitative case study and the dilemma of data saturation. A thorough review of the literature that incorporated 62 references was made. Sixty-one (98\%) of total references incorporated in the study are peer-reviewed, while (50\%) are peer-reviewed journals that are within the last 5 years.

\subsection{Analysis and synthesis of contrasting researchers of data saturation}

The principles and concepts of data saturation in terms of no new data, no new themes, no new coding, and ability to replicate the study is generally adopted by researchers of qualitative case study. Fusch and Ness argue that data saturation is not a unified phenomenon and that there is a need to be explicit in the study design regarding how data saturation will be reached [22]. They contend that it may be reached when there is enough information to replicate the study, or when further coding is no longer feasible. According to Mosia and Phasha, data saturation is reached when the transcripts are no longer revealing information, thereby making a novel contribution to the researchers' understanding of the topic, as revealed by the themes and sub-themes [42]. The consensus of many qualitative case study researchers on data saturation, is that data saturation is reached when additional input from new participants no longer leads to: new information [20], [37], [43] and [49], new concepts in the transcript that suggests robust data consistency [19], new themes [16] or new understanding of the topic, as revealed by the themes and sub-themes [22].

Some other researchers claimed that data saturation is reached when there is enough information to replicate the study [45] and [58], and when further coding is no longer feasible [28]. However, in a case study, there is also a general opinion by some researchers that it may be best to secure data saturation by thinking of data in terms of rich (high quality) and thick (enough quantity) data rather than sample size alone [24] and [56]. The concept of data saturation based on rich and thick rather than sample size alone is widely advocated [5]. This idea was supported by Kandasamy, et al who calls for the use of multiple sources of data in qualitative case study [31]. This idea was also supported by Stålberg and Fundin in the sense that without adoption of multiple sources of data, a single case study that is limited to one case organization may lack external validity [52]. Other researchers that supported this view recommended various strategies to ensure data saturation that included methodological triangulation and member checking to secure data saturation [30] and [44], and to secure the validity and justification of data interpretation [30], [50] and [62].

Others claimed that through data triangulation, reliability of the results and attainment of data saturation is enhanced [57]. For example, it is possible to reduce the number of interviews by collecting data from other sources like observations/open-ended survey and such. According to Visser, et al, methodological triangulation for a case study that employs both interviews data and data from other sources can be used to further secure data saturation [57]. While triangulation builds coherent justification of interpretation, rich thick description facilitated through the provision of verbatim quotes to allow readers to assess the strength of the relation between data and analysis can impact data saturation [35]. Various strategies employed to ensure the rigor of the work and data saturation may include triangulation, member checking, reflexivity and peer debriefing [44]. Methodological triangulation that incorporated one-on-one interviews as well as a review of secondary data such as documentaries, web searches, etc., were applicable, 
has been recommended by some qualitative single case researchers [5]. According to Azmat and Rentschler, methodological triangulation of data from different sources and methods was useful in confirming, complementing or disconfirming perspectives obtained from study in relation to securing data saturation [5].

\section{Conclusion}

The concept of data saturation is hard to define and inconsistently assessed and reported in literature possibly because it has diverse meaning to many researchers. Qualitative researchers are unlikely to agree on exact sample size required or one style procedure to reach saturation because study designs are not universal. However, researchers do agree on some general principles and concepts to reach data saturation: no new data, no new themes, no new coding, and ability to replicate the study. Failure to reach data saturation has an impact on the quality of the research conducted and has a negative impact on the validity on one's research. Findings show that whether or not saturation is reached, it does not invalidate the findings; rather the findings should include the note that the phenomenon has not yet been fully explored. Various strategies employed to ensure the rigor of the work and data saturation may include triangulation, member checking, audit trials, reflexivity, peer debriefing and reaching data saturation. Also, assuming a working sample size before data collection based on assessment facilitated by past related qualitative studies may be expedient as there are no correct absolute measurements to form a construct.

\section{Compliance with ethical standards}

\section{Acknowledgments}

I would like to acknowledge Dr. Gail Miles, the Program Director at Walden University, who was my chair during my doctoral dissertation at Walden University, for all her encouragement in getting me through this process of data saturation.

\section{References}

[1] Afsharkazemi M, Manouchehri J, Salarifar M, Nasiripour AA. Key factors affecting the hospital performance: a qualitative study using fuzzy logic. Quality and Quantity. 2013; 47(6): 3559-3573.

[2] Ang CK, Embi MA, Yunus MM. Enhancing the quality of the findings of a longitudinal case study: Reviewing trustworthiness via ATLAS. The Qualitative Report. 2016; 21(10): 1855-1867.

[3] Atif M, Javaid S, Farooqui M, Sarwar MR. Rights and Responsibilities of Tuberculosis Patients, and the Global Fund: A Qualitative Study. PLoS One. 2016; 11(3): 1-15.

[4] Auger MD. Cultural continuity as a determinant of indigenous peoples' health: A metasynthesis of qualitative research in Canada and the United States. International Indigenous Policy Journal. 2016; 7(4).

[5] Azmat F, Rentschler R. Gender and Ethnic Diversity on Boards and Corporate Responsibility: The Case of the Arts Sector. Journal of Business Ethics. 2017; 141(2): 317-336.

[6] Baker SE, Edwards R. How many qualitative interviews is enough? Expert voices and early career reflections on sampling and cases in qualitative research. National Centre for Research Methods Review Paper. 2012; 1-42.

[7] Balasubramanian NA. Perception of Adolescence on Healthy lifestyle and Factors contributing to Health and its Barrier: Grounded theory approach. Journal of Nursing Education and Research. 2017; 7(1): 26-30.

[8] Bell EE. A Narrative Inquiry: A Black Male Looking to Teach. The Qualitative Report. 2017; 22(4): 1137-1150.

[9] Benzer JK, Beehler S, Cramer IE, Mohr DC, Charns MP, Burgess JF. Between and within-site variation in qualitative implementation research. Implementation Science. 2013; 8(1): 4-28.

[10] Billups F. The Quest for Rigor in Qualitative Studies: Strategies for Institutional Researchers. The NERA Researcher. 2014; 52(1): 1-5.

[11] Birt L, Scott S, Cavers D, Campbell C, Walter F. Member Checking: A Tool to Enhance Trustworthiness or Merely a Nod to Validation? Qualitative Health Research. 2016; 26(13): 1802-1811.

[12] Bowen GA. Naturalistic inquiry and the saturation concept: A research note. Qualitative Research. 2008; 8(1): $137 ? 152$. 
[13] Burda M, van den Akker M, van der Horst F, Lemmens P, Knottnerus JA. Collecting and validating experiential expertise is doable but poses methodological challenges. Journal of Clinical Epidemiology; Elmsford. 2016; 72(1): 10-15.

[14] Caretta MA. Member checking: A feminist participatory analysis of the use of preliminary results pamphlets in cross-cultural, cross-language research. Qualitative Research. 2015; 16(3): 305-318.

[15] Charlebois K, Palmour N, Knoppers BM. The Adoption of Cloud Computing in the Field of Genomics Research: The Influence of Ethical and Legal Issues. PLoS One. 2016; 11(10): 1-33.

[16] Coorey GM, Neubeck L, Usherwood T, Peiris D, Kiyimba S, Lau AYS, Redfern J. Implementation of a consumerfocused eHealth intervention for people with moderate-to-high cardiovascular disease risk: protocol for a mixedmethods process evaluation. BMJ Open. 2017; 7(1): 1-10.

[17] Crouch M, McKenzie H. The logic of small samples in interview-based qualitative research. Social Science Information. 2006; 45(4): 483-499.

[18] Dare AJ, Lee KC, Bleicher J, Elobu AE, Kamara TB, Liko O, Luboga S, Danlop A, Kune G, Hagander L, Leather AJ M, Yamey G. Prioritizing surgical care on national health agendas: A Qualitative Case Study of Papua New Guinea, Uganda, and Sierra Leone. PLoS Medicine. 2016; 13(5): 1-25.

[19] Dedios MC, Esperato A, De-Regil LM, Juan PP, Norris SL. Improving the adaptability of WHO evidence-informed guidelines for nutrition actions: results of a mixed methods evaluation. Implementation Science. 2017; 12(1): 3951 .

[20] Eid A, Quinn D. Factors predicting training transfer in health professionals participating in quality improvement educational interventions. BMC Medical Education. 2017; 17(1): 1-9.

[21] Ergene O, Yazici EZ, Delice A. Investigation of validity and reliability works in postgraduate mathematics theses that adopt qualitative research in Turkey: Functions of data collection tool. SHS Web of Conferences. 2016; 26(1): 1-7.

[22] Fusch PI, Ness LR. Are We There Yet? Data Saturation in Qualitative Research. The Qualitative Report. 2015; 20(9): 1408-1416.

[23] Galvin R. How many interviews are enough? Do qualitative interviews in building energy consumption research produce reliable knowledge? Journal of Building Engineering. 2015; 1: 2-12.

[24] Gentles SJ, Charles C, Ploeg J, McKibbon KA. Sampling in qualitative research: Insights from an overview of the methods literature. The Qualitative Report. 2015; 20(11): 1772-1789.

[25] Ghiga I, Stalsby CL. Struggling to be a defender of health -a qualitative study on the pharmacists' perceptions of their role in antibiotic consumption and antibiotic resistance in Romania. Journal of Pharmaceutical Policy and Practice. 2016; 9(1): 1-10.

[26] Gonzalo JD, Heist BS, Duffy BL, Dyrbye L, Fagan MJ, Ferenchick G, Harrell H, Hemmer PA, Kernan WN, Kogan JR, Rafferty C, Wong R, Elnicki DM. The art of bedside rounds: A multi-center qualitative study of strategies used by experienced bedside teachers. Journal of General Internal Medicine. 2013; 28(3): 412-420.

[27] Grieb SD, Eder MM, Smith KC, Calhoun KTD. Qualitative Research and Community-Based Participatory Research: Considerations for Effective Dissemination in the Peer-Reviewed Literature. Progress in Community Health Partnerships. 2015; 9(2): 275-282.

[28] Guest G. How Many Interviews Are Enough? An Experiment with Data Saturation and Variability. Field Methods. 2006; 18(1): 59-82.

[29] Hagaman AK, Wutich A. How many interviews are enough to identify metathemes in multisited and crosscultural research? Another perspective on guest, Bunce, and Johnsons (2006) landmark study. Field Methods. 2016.

[30] Hoque Z, Covaleski MA, Gooneratne TN. Theoretical triangulation and pluralism in research methods in organizational and accounting research. Accounting, Auditing \& Accountability Journal. 2013; 26(7): 1170-1198.

[31] Kandasamy S, Vanstone M, Oremus M, Hill T, Wahi G, Wilson JA, Davis D, Jacobs R, Anglin R, Anand SS. A Case Study of a Methodological Approach to Cocreating Perinatal Health Knowledge Between Western and Indigenous Communities. International Journal of Qualitative Methods. 2017; 16(1): 1-11. 
[32] Kass GV, Mood AM, Graybill FA, Boes DC. Introduction to the Theory of Statistics, 3rd ed. Journal of the American Statistical Association volume. 1974; 69(348): 348-1050.

[33] Kerr C, Nixon A, Wild D. Assessing and demonstrating data saturation in qualitative inquiry supporting patientreported outcomes research. Expert Review of Pharmacoeconomics\& Outcomes Research. 2010; 10(3): $269-281$.

[34] Kline TJB. Sample Issues, Methodological Implications, and Best Practices. Canadian Journal of Behavioural Science. 2017; 49(2): 71-77.

[35] Kontos P, Alibhai S, Karen-Lee M, Brooks D, Romeo C, Parsons T, Jassal SV, Thomas A, Binns M, Naglie G. A prospective 2-site parallel intervention trial of a research-based film to increase exercise amongst older hemodialysis patients. BMC Nephrology. 2017; 18(1): 37-47.

[36] Kruth JG. Five qualitative research approaches and their applications in parapsychology. Journal of Parapsychology. 2015; 79(2): 219-233.

[37] Latham JR. A framework for leading the transformation to performance excellence part: CEO perspectives on forces, facilitators, and strategic leadership systems. Quality Management Journal. 2013; 20(2): 12-33.

[38] Malcolm PM. Peer support in mental health: a narrative Review of its relevance to social work. Egyptian Journal of Social Work. 2017; 4(1): 19-40.

[39] Marshall B, Cardon P, Poddar A, Fontenot R. Does sample size matter in qualitative research? A review of qualitative interviews in is research. The Journal of Computer Information Systems. 2013; 54(1): 11-22.

[40] Martinus K, Hedgcock D. The methodological challenge of cross-national qualitative research: comparative case study interviews in Australia and Japan. Qualitative Research Journal. 2015; 15(3): 373-386.

[41] Mood AM, Graybill FA, Boes DC. Introduction to the Theory of Statistics, 3rd McGrawhillKogakusha, Ltd. 1974.

[42] Mosia PA, Phasha N. Access to curriculum for students with disabilities at higher education institutions: How does the National University of Lesotho fare? Access to curriculum for students with disabilities at higher education institutions: How does the National University of Lesotho fare? African Journal of Disability; Pretoria. $2017 ; 6(1): 1-13$

[43] Natoli R, Jackling B, Siddique S. Insights into Departure Intention: A Qualitative Case Study. Education Research and Perspectives. 2015; 42(1): 459-490.

[44] ODonnell P, Tierney E, Austin O, Nurse D, MacFarlane A. Exploring levers and barriers to accessing primary care for marginalised groups and identifying their priorities for primary care provision: a participatory learning and action research study. International Journal for Equity in Health. 2016; 15(1): 197-212.

[45] O'Reilly M, Kiyimba N. Unsatisfactory Saturation: A critical exploration of the notion of saturated sample sizes in qualitative research. Qualitative Research. 2013; 13(2): 190-197.

[46] Privizzini A. The Child Attachment Interview: A Narrative Review. Frontiers in Psychology. 2017; 8(1).

[47] Ray SA. Street Child's Perspective: A Grounded Theory Study of How Street Children Experience and Cope with Grief. The Qualitative Report. 2017; 22(1): 291-308.

[48] Scarnato JM. The value of digital video data for qualitative social work research: A narrative review Qualitative Social Work: Research and Practice. 2017.

[49] Schäfer I, Pawels M, Küver C, Pohontsch NJ, Scherer M, den Bussche H, Kaduszkiewic H. Strategies for Improving Participation in Diabetes Education. A Qualitative Study. PLoS One. 2014; 9(4): 1-7.

[50] Seth FP, Mustonen-ollila E, Taipale O, Smolander K. Software quality construction in 11 companies: an empirical study using the grounded theory Software Quality Journal. 2015; 23(4): 627-660.

[51] Simpson A, Quigley CF. Member Checking Process with Adolescent Students: Not Just Reading a Transcript. The Qualitative Report. 2016; 21(2): 377-392.

[52] Stålberg L, Fundin A. Exploring a holistic perspective on production system improvement. The International Journal of Quality \& Reliability Management. 2016; 33(2): 267-283.

[53] Taylor R, Thomas-Gregory A. Case study research. Nursing Standard; London. 2014; 29(41): 36-40.

[54] Thomas DR. Feedback from research participants: are member checks useful in qualitative research? Qualitative Research in Psychology. 2016; 14(1): 23-41. 
[55] Thomsen T, Beyer N, Aadahl M, Hetland ML, Lappenthin K, Midtgaard J, Esbensen BA. Sedentary behaviour in patients with rheumatoid arthritis: A qualitative study. International Journal of Qualitative Studies on Health and Well-Being. 2015; 10(1): 1-10.

[56] Tran V, Porcher R, Tran V, Ravaud P. Predicting data saturation in qualitative surveys with mathematical models from ecological research. Journal of Clinical Epidemiology. 2017; 82(1): 71-78.

[57] Visser LM, Bleijenbergh IL, Benschop YWM, Van Riel ACR, Bloem BR. Do online communities change power processes in healthcare? Using case studies to examine the use of online health communities by patients with Parkinson's disease. BMJ Open. 2016; 6(11): 1-6.

[58] Walker JL. The use of saturation in qualitative research. Canadian Journal of Cardiovascular Nursing. 2012; 22(2): 37-46.

[59] Willgens AM, Cooper R, Jadotte D, Lilyea B, Langtiw C, Obenchain-Leeson A. How to Enhance Qualitative Research Appraisal: Development of the Methodological Congruence Instrument. The Qualitative Report. 2016; 21(12): 2380-2395.

[60] Wong ZY, Hassali MA, Alrasheedy AA, Saleem F, M-Yahaya AH, Aljadhey H, Khan TM. Medical specialists' knowledge, perceptions and views about generic medicines in Malaysia: Findings from a qualitative study and the implications. Journal of Generic Medicines. 2015; 12(2): 60-73.

[61] Wray N, Markovic M, Manderson L. Researcher saturation: the impact of data triangulation and intensiveresearch practices on the researcher and qualitative research process.Qualitative health research. 2007; 17(10): 1392-1402.

[62] Yilmaz B, Özkan Y. An Investigation into English Language Instructors' and Students' Intercultural Awareness. The Qualitative Report. 2016; 21(10): 1932-1959.

\section{Authors short Biography}

Dr. Felix Chukwuma Aguboshim holds a doctoral degree is Information Technology.
He is currently a chief lecturer in the department of computer science, Federal
Polytechnic Oko, Nigeria, where he worked as the Head of Department of Computer
Science and Director of Campus. His is also an adjoining lecturer at the University
of America Study Centre in Nigeria.

